\title{
Effects of Salvia miltiorrhiza extract with supplemental liquefied calcium on osteoporosis in calcium-deficient ovariectomized mice
}

Bongkyun Park', Hae Seong Song ${ }^{1}$, Jeong Eun Kwon', Se Min Cho', Seon-A Jang ${ }^{1}$, Mi Yeon Kim² and Se Chan Kang ${ }^{1 *}$

\begin{abstract}
Background: Extracts from Salvia miltiorrhiza Bunge have been used in traditional Asian medicine to treat coronary heart disease, chronic renal failure, atherosclerosis, myocardial infraction, angina pectoris, myocardial ischemia, dysmenorrheal, neurasthenic insomnia, liver fibrosis and cirrhosis. The aim of the study was to investigate the antiRANK signal effect of the combination of S.miltiorrhiza Bunge (SME) and liquefied calcium (LCa) supplement with ovariectomized (OVX-SML) mice, a osteoporosis animal model. Results were compared to 17ß-estradiol $\left(E_{2}\right)$ treatment.

Methods: A total of 70 female ICR strain mice (7 weeks) were randomly divided into 10 groups with 7 mice in each group as follows: (1) sham-operated control mice (sham) received daily oral phosphate-buffered-saline (PBS) of equal volumes through oral administration. (2) OVX mice received a daily oral administration of PBS (OVX). (3) OVX mice treated daily with $50 \mathrm{mg} / \mathrm{kg}$ b.w./ day of SME (4) with $100 \mathrm{mg} / \mathrm{kg} \mathrm{b.w./day} \mathrm{of} \mathrm{SME} \mathrm{or} \mathrm{(5)} \mathrm{with} 200 \mathrm{mg} / \mathrm{kg}$ b.w./day of SME via oral administration. (6) OVX mice treated daily with $50 \mathrm{mg} / \mathrm{kg}$ b.w./day of SML (7) with $100 \mathrm{mg} / \mathrm{kg}$ b.w./day of SML or (8) with $200 \mathrm{mg} / \mathrm{kg}$ b.w./day of SML via oral administration. (9) OVX mice treated daily with $10 \mathrm{ml} / \mathrm{kg}$ b.w./day of LCa (10) OVX mice received i.p. injections of $17 \beta$-estradiol $\left(E_{2}\right)(0.1 \mathrm{mg} / \mathrm{kg}$ b.w./day) three times per week for 12 weeks.

Results: micro-CT analysis revealed that oral administration of SML inhibited tibial bone loss, sustained trabecular bone state, and ameliorated bone biochemical markers. In addition, SML administration compared to SEM and LCa reduced serum levels of RANKL, osteocalcin and BALP through increased serum levels of OPG and $E_{2}$ in OVX mice. SML also had more beneficial effects on protection of estrogen-dependent bone loss through blocking expression of TRAF6 and NFTAc1 and produces cathepsin $\mathrm{K}$ and calcitonin receptor to develop osteoclast differentiation.

Conclusion: These data suggest that S. miltiorrhiza Bunge combined with liquefied calcium supplement has an inhibitory activity in OVX mice. This result implies the possibility of a pharmacological intervention specifically directed toward a disease such as osteoporosis where decreased bone strength increases the risk of a broken bone.
\end{abstract}

Keywords: Salvia miltiorrhiza Bunge, Liquefied calcium supplement, Ovariectomized mice, RANKL, OPG

\footnotetext{
* Correspondence: sckang@khu.ac.kr

${ }^{1}$ Department of Oriental Medicine and Biotechnology, College of Life

Science, Kyung Hee University, Yongin-si 17104, Republic of Korea

Full list of author information is available at the end of the article
} 


\section{Background}

Osteoporosis is often regarded as a compensatory disease for reduced bone strength and is influenced by mechanisms controlling bone remodeling [1, 2]. In women, remodeling mechanisms are significantly influenced by ovarian function and are remarkably changed by ovarian aging and reproductive damage. These signs are related to an estrogen deficiency, and not a genetic or mechanical cause [3]. In addition, it has been reported that osteoporosis can be classified as two types. Type I osteoporosis is the most common in postmenopausal women and is related to an estrogen deficiency. Type II osteoporosis is senile osteoporosis, caused by aging, and is largely due to decreased dietary calcium and vitamin $\mathrm{D}$ or increased parathyroid gland activity $[4,5]$.

Many experimental models have been indicated to induce osteoporosis. Among these models, the mice ovariectomized (OVX) model is the most well-known and popular model to investigate bone loss in proximal tibia, the distal femur, and the lumbar vertebrae [6]. In addition, FDA guidelines have been demonstrated that the characteristics of bone loss in the OVX model simulate the bone alterations following menopause or oophorectomy in human. Therefore, this model is appropriate to exploit the preventive potential of new therapeutic agents [7]. There are also some alternative animal experimental models to induce osteoporosis. In the rat model, alcohol abuse increased the pathogenesis of inhibited bone mass [8]. A high cholesterol or calcium deficient model induced osteoporosis through inhibiting osteoblast differentiation and growth $[9,10]$. The diabetic related osteopenia has also been widely examined in several experimental investigation $[11,12]$.

Estrogen plays an essential role in bone homeostasis and skeletal growth. Estrogen deficiency induces chronic inflammatory conditions by increasing various cytokines, free radicals, and growth factors, which produce an altered bone microenvironment by increasing bone loss and osteoclast formation [4, 13-15]. Moreover, estrogen reduces intestinal calcium (Ca) absorption and $\mathrm{Ca}$ availability $[16,17]$. Accordingly, hormone replacement therapy (HRT) has been used for postmenopausal osteoporosis. However, the long-term usage of estrogens like $17 \beta$-estradiol in postmenopausal women gives rise to various side effects, such as gastrointestinal tolerance and/or breast, ovarian, and endometrial cancers [18-20]. There has been recent interest in plant-derived compounds that have a comparable structure to estrogen and a similar ability to bind estrogen receptors [21]. The estrogen-similar effects of these compounds represent an alternative approach to replace or augment HRT for managing osteoporosis [22].
Salvia miltiorrhiza Bunge (SME) is a native species of a perennial plant in the genus Salvia from China, Japan, and Korea [23]. It has been known as a traditional herbal medicine for anti-inflammatory activity in rat carrageenan-induced paw oedema and adjuvantinduced arthritis [24], anti-oxidation activity in high fat diet induced atheroscleotic mice [25], and antiosteoporotic efficacy on the Chinese herbal prescriptions including Salvia miltiorrhiza in clinical trial of menopause women [26]. The important bioactive constituents of $S$. miltiorrhiza are tanshinones, salvianolic acid B, and danshensu [27]. Tanshinone IIA and salvianolic acid B in $S$. miltiorrhiza are the major active constituents and have antioxidant effects [27]. It has also been shown that tanshinone IIA inhibits bone resorption through attenuating the differentiation and activity of osteoclasts in vitro [28] and through the association of lipid peroxidation products with DNA in liver cells [29]. Salvianolic acid B has remarkable antioxidant activity, which has been reported in cerebral and heart ischemia in vivo; it also decreases malondialdehyde level and inhibits brain and heart damage in vivo [30, 31].

Calcium supplements ( $\mathrm{LCa}$ ) can be classified as natural supplements derived from shells (e.g., eggshells, oyster shells, etc.) or as synthetic supplements like calcium carbonate and calcium citrate. Synthetic calcium can be produced in huge amounts at low cost but has very low solubility; therefore, the solubility of synthetic calcium supplements must be increased for more effective absorption into the body [32-34]. To this end, liquefied calcium supplements have been shown to increase bone mineral density and bone mineral content compared to insoluble calcium supplements in clinical investigations with growing rats $[35,36]$. Moreover, the combination with $\mathrm{LCa}$ and hormone replacement therapy (HRT) has been demonstrated that the treatment of postmenopausal women with low bone mass or bone fracture history [22].

Based on these studies, the combinational effect of SME and LCA on osteoporosis has not yet been demonstrated. The present study suggests that S. miltiorrhiza Bunge (SME) extract combined with liquefied calcium supplement ( $\mathrm{LCa}$ ) may have anti-osteoporotic activity in improving bone mineral density. To evaluate the therapeutic potential of a combination of SME and LCa to treat postmenopausal osteoporosis, we investigated the inhibitory effect of a combination of SME and LCa on ovariectomized mice used as a postmenopausal model.

\section{Methods}

Preparation of sample extracts

Dried S. miltiorrhiza Bunge was provided by Kyemyeong Foodex Co. (Daegu, Korea). The plant was identified and 
authenticated on the basis of its macroscopic and microscopic characteristics, and validated using HPLC as outlined in the Supplemental Experimental Procedures (Additional file 1: Fig. S1). Chemical analysis with thin layer chromatography (TLC) was employed in order to establish the constant composition of S. miltiorrhiza Bunge in accordance with the Korean Pharmacopoeia (KP), a statute for pharmaceuticals established by the Korean government for improvement of public health. $S$. miltiorrhiza Bunge (1000 g) (SME) was extracted with water at room temperature. Liquefied calcium supplements (LCa) $(60 \mathrm{mg} / \mathrm{ml}$, over $90 \%$ ionizing ratio) were prepared from calcium materials (seaweed powder, egg shells, and oyster shells) by soaking in vinegar [37] and were provided by Kyemyeong Foodex Co. (Daegu, Korea) [32]. The combination (SML) of SME and LCa was composed in demineralized water (SME 50, 100, $200 \mathrm{mg} /$ body weight $(\mathrm{kg}) /$ day; LCa $10 \mathrm{ml} /$ body weight $(\mathrm{kg}) /$ day, concentration $60 \mathrm{mg} / \mathrm{kg}$ ).

\section{Animal care}

Female 6-week-old outbred ICR mice weighing 20-23 g were purchased from Korea Laboratory Animal Co. (Daejeon, Korea) and were housed for 7 days prior to the experiment. They were housed in solid-bottomed plastic cages designed to allow easy access to standard laboratory food and water. Mice were kept in sanitary ventilated animal rooms with a controlled temperature $\left(25 \pm 1{ }^{\circ} \mathrm{C}\right)$ and regular light cycle (12 h light: $12 \mathrm{~h}$ dark). The body weight of mice was monitored every 3 days for 12 weeks, and the mice were sacrificed by $\mathrm{CO}_{2}$ to measure weight of uterus, thymus and spleen. Animal experiments were conducted in accordance with the current ethical regulations for animal care and use at Kyung Hee University (KHUASP(SE)-16-003).

\section{Postmenopausal osteoporosis induced by ovariectomy (OVX)}

Mice were surgically ovariectomized under anesthesia with tiletamine/zolazapam (Virbac Korea, Seoul, Korea) and xylazine $\mathrm{HCl}$ (Bayer Korea, Kyungkido, Korea) using a ventral approach. At 7 weeks of age, mice were randomly divided into 10 groups of 7 mice as follows: (1) sham-operated control mice (sham) received daily oral phosphate-buffered saline (PBS) of equal volume. (2) OVX mice received a daily oral administration of PBS (OVX). (3) OVX mice treated daily with $50 \mathrm{mg} / \mathrm{kg}$ b.w. of SME, (4) with $100 \mathrm{mg} / \mathrm{kg}$ b.w. of SME, or (5) with $200 \mathrm{mg} / \mathrm{kg}$ b.w. of SME via oral administration. (6) OVX mice treated daily with $50 \mathrm{mg} / \mathrm{kg}$ b.w. of SML, (7) with $100 \mathrm{mg} / \mathrm{kg}$ b.w. of SML, or (8) with $200 \mathrm{mg} / \mathrm{kg}$ b.w. of SML via oral administration. (9) OVX mice treated daily with $10 \mathrm{ml} / \mathrm{kg}$ b.w. of LCa. (10) OVX mice received i.p. injections of $17 \beta$-estradiol $\left(\mathrm{E}_{2}\right)(0.1 \mathrm{mg} / \mathrm{kg}$ b.w. $)$ three times per week. All mice received their respective treatment for 12 weeks. At the end of the treatment period, the mice were subjected to micro-CT analysis and were sacrificed at the designated time point to provide adequate serum for assays.

\section{Micro-CT bone analysis}

To evaluate structural loss in bone architecture, the proximal and distal parts of the right tibias were scanned by in vivo micro-computed tomography (Micro-CT, Skyscan1076, Skyscan, Antwerp, Belgium). The scan conditions were set at an aluminum filter of $0.5 \mathrm{~mm}, \mathrm{X}$ ray voltage of $50 \mathrm{Kv}$, X-ray current of $200 \mathrm{~mA}$, and exposure time of $360 \mathrm{~ms}$. During each scan, mice were maintained under anesthesia via inhalation with isoflurane (Hana Pharm, Seoul, Korea). Mice were placed in a chamber filled with $5 \%$ isoflurane in oxygen for $5 \mathrm{~min}$, after which the isoflurane was adjusted to $1.5 \%$ to maintain anesthesia [38]. The data were then digitized using a frame grabber, and the resulting images were transmitted to a computer for analysis using Comprehensive TeX Archive Network (CTAN) topographic reconstruction software. Total volume indicated the inner area of cortical bone. Trabecular bone volume indicated the total trabecular bone within the total volume. Bone volume percentage was calculated by dividing the trabecular bone volume by the total volume. The measured cortical bone parameters were bone volume fraction (BV), mean polar moment of inertia (MMI), cross section thickness (Cs.Th), and bone mineral density (BMD). The measured trabecular bone parameters were bone volume fraction (BV/TV), trabecular thickness (Tb.Th), trabecular separation (Tb.Sp), trabecular number (Tb.N), trabecular bone pattern factor (Tb.Pf), specific bone surface (BS/BV), structure model index (SMI), and bone mineral density (BMD).

\section{Serum analysis}

At sacrifice, samples of whole blood were collected by cardiac puncture, and blood was allowed to clot for $30 \mathrm{~min}$. Serum was then separated via centrifugation at $1500 \mathrm{~g}$ for $10 \mathrm{~min}$. Markers of bone turnover present in the serum were measured using enzyme linked immunosorbent assay (ELISA) kits for RANKL and OPG (R\&D Systems, Minneapolis, MN, USA) and for $\mathrm{E}_{2}$, osteocalcin, and BALP (Biomedical Technologies Inc., Stoughton, MA, USA). All ELISA procedures were performed according to the manufacturers' protocols.

\section{Isolation of total RNA and quantitative real-time PCR}

Following the manufacturer's protocol, total RNA was extracted from bone marrow isolated from OVX mice using Trizol Reagent. Isolated RNA ( $1 \mathrm{mg} / \mathrm{ml})$ was reverse transcribed using a SuperScript II kit for cDNA 
synthesis. The cDNA was subjected to quantitative realtime (qRT)-PCR using thermocyclers from Applied Biosystems (Franklin Lakes, NJ, USA). For each RNA sample, the expression of $\beta$-actin was quantified by realtime RT-PCR, and a Ct method was used to estimate the differential gene expression between samples. Oligonucleotide sequences of primers used for RT-PCR using SYBR Green technology were as follows: Cathepsin K forward (5'-CACCCAGTGGGAGCTATGGAA-3') and Cathepsin $\mathrm{K}$ reverse (5'-GCC TCCAGGTTATGGGCA GA-3'); Calcitonin receptor (CalcR) forward (5'-AGGC AGACCCAAATG CTGTAATG-3') and Calcitonin receptor reverse (5'-TTGGTGATAGGTTCTTGGTGA CCTC-3'); TRAF6 forward (5'-TTAAATGTCGGCATT CTCAGGGTA-3') and TRAF6 reverse (5'-TTGTGACC GAGACTC TCC CAAG-3'); NFATc1 forward (5'-GCT TCACCCATTTGCTCCAG- $3^{\prime}$ ) and NFATc1 reverse (5'-ATGGTGTGGAAATACGGTTGGTC-3'); $\quad \beta$-actin forward (5'-TCACCCACACTGTGCCCATCTACGA-3') and $\beta$-actin reverse (5'-GGATGCCACAGGATTCCAT ACCCA-3').

\section{Statistical analysis}

Each result is reported as mean \pm standard error of the mean (SEM). One-way analysis of variance (ANOVA) was used to determine the significance between groups, after which a modified t-test and two-way ANOVA and the Newman-Keuls test were used to analyze differences among OVX groups. Significant differences were stated for $p$ values. $(p<0.05)$.

\section{Results}

Effects of SML on body weight and uterus weight in OVX mice

We investigated the effects of $S$. miltiorrhiza combined with liquefied calcium supplement (SML) in vivo using
OVX mice. Rates of weight change were monitored every week. As shown in Table 1, body weight was significantly increased in the OVX group. However, oral administration of $200 \mathrm{mg} / \mathrm{kg} \mathrm{SML}$ and treatment with $E_{2}$ attenuated the increased body weight. In addition, uterine weight and uterine/body weight ratio in the OVX group were remarkably decreased compared to the sham group. Oral administration of SML at 100 or $200 \mathrm{mg} / \mathrm{kg}$ and treatment of $E_{2}$ significantly increased the uterine/body weight ratio. Therefore, SML administration affected the body and uterine weights in OVX mice (Fig. 1). We next examined the effects of SML on the immune system. The weights of the thymus and spleen were significantly influenced by removal of the ovaries. The thymus weight in the OVX group was considerably increased compared to that in the sham group. However, it was suppressed by oral administration of SML at 100 or $200 \mathrm{mg} / \mathrm{kg}$ and by $E_{2}$ treatment. In contrast, the spleen weight in the OVX group was decreased but was restored by oral administration of SML at 100 or $200 \mathrm{mg} / \mathrm{kg}$ and by $E_{2}$ treatment in OVX mice (Table 2).

\section{Effects of SML on the structural characteristics of cortical bone}

To determine the effects of SML on OVX-induced cortical bone structural properties, the tibia of each mouse was measured for structural parameters. Bone volume density $\left(\mathrm{BV}, \mathrm{mm}^{3}\right)$, mean polar moment of inertia (MMI, $\left.\mathrm{mm}^{4}\right)$, cross-section thickness (Cs.Th, $\mathrm{mm}$ ), and bone mineral density (BMD, $\mathrm{g} / \mathrm{cm}^{3}$ ) were scanned and calculated using micro-CT images (Fig. 2a). The measurements of Cs.Th, BV, MMI, and BMD did not change between the sham group and the OVX group. Moreover, the structural parameters were not significantly changed by oral administration of SML as well as each extract (Fig. 2 b, c, d and e).

Table 1 Effects of SML on body weight in OVX mice

\begin{tabular}{|c|c|c|c|c|c|}
\hline \multicolumn{2}{|c|}{ Period Groups } & \multicolumn{3}{|l|}{ Body weight (g) } & \multirow{2}{*}{$\begin{array}{l}\text { Body Weight Gains } \\
\text { During Treatment (g) }\end{array}$} \\
\hline & & \multirow{2}{*}{$\frac{\text { At OVX }^{a}}{23.14 \pm 1.23^{b}}$} & \multirow{2}{*}{$\frac{\text { At Initial Treatment }^{a}}{24.57 \pm 0.96^{c}}$} & \multirow{2}{*}{$\frac{\text { At Sacrifice }^{a}}{26.71 \pm 2.51^{d}}$} & \\
\hline Sham & & & & & $2.14 \pm 1.1^{c d}$ \\
\hline \multirow[t]{9}{*}{ OVX } & - & $24.29 \pm 2.1^{\mathrm{a}}$ & $29.67 \pm 1.15^{\mathrm{a}}$ & $36.59 \pm 1.98^{\mathrm{a}}$ & $6.92 \pm 1.8^{a b}$ \\
\hline & SME 50 mg/kg & $24.37 \pm 1.53^{a}$ & $28.93 \pm 0.82^{\mathrm{ab}}$ & $35.71 \pm 1.15^{\mathrm{ab}}$ & $6.78 \pm 1.17^{\mathrm{ab}}$ \\
\hline & SME 100 mg/kg & $24.1 \pm 1.62^{\mathrm{a}}$ & $28.71 \pm 0.96^{\mathrm{ab}}$ & $35.95 \pm 1.98^{\mathrm{ab}}$ & $7.24 \pm 0.82^{a}$ \\
\hline & SME 200 mg/kg & $23.94 \pm 0.95^{\mathrm{ab}}$ & $28.5 \pm 0.84^{b}$ & $36.1 \pm 2.23^{\mathrm{a}}$ & $7.6 \pm 1.94^{a}$ \\
\hline & SML 50 mg/kg & $24.22 \pm 1.15^{\mathrm{a}}$ & $29.14 \pm 1.11^{a}$ & $35.74 \pm 1.92^{\mathrm{ab}}$ & $6.6 \pm 1.3^{b}$ \\
\hline & SML 100 mg/kg & $24.41 \pm 1.42^{\mathrm{a}}$ & $28.59 \pm 1.26^{\mathrm{ab}}$ & $36.25 \pm 2.68^{a}$ & $7.7 \pm 2.21^{\mathrm{a}}$ \\
\hline & SML 200 mg/kg & $24.37 \pm 1.27^{\mathrm{a}}$ & $28.63 \pm 1.29^{\mathrm{ab}}$ & $32.59 \pm 2.11^{b}$ & $3.96 \pm 2.05^{c}$ \\
\hline & LCa 10 ml/kg & $24.51 \pm 0.85^{a}$ & $27.92 \pm 2.21^{b c}$ & $34.93 \pm 1.29^{\mathrm{ab}}$ & $7.01 \pm 1.82^{a}$ \\
\hline & E2 0.1 mg/kg & $24.62 \pm 1.09^{\mathrm{a}}$ & $28.15 \pm 1.42^{b}$ & $30.21 \pm 1.38^{c}$ & $2.06 \pm 2.13^{d}$ \\
\hline
\end{tabular}

Values are given as mean \pm S.E.M. $n=7$ for all groups. ${ }^{a}$ All animals were overnight fasted; Means with different superscripts (a, b, $c$, d) are significantly different at $p<0.05$ in pairwise comparisons 


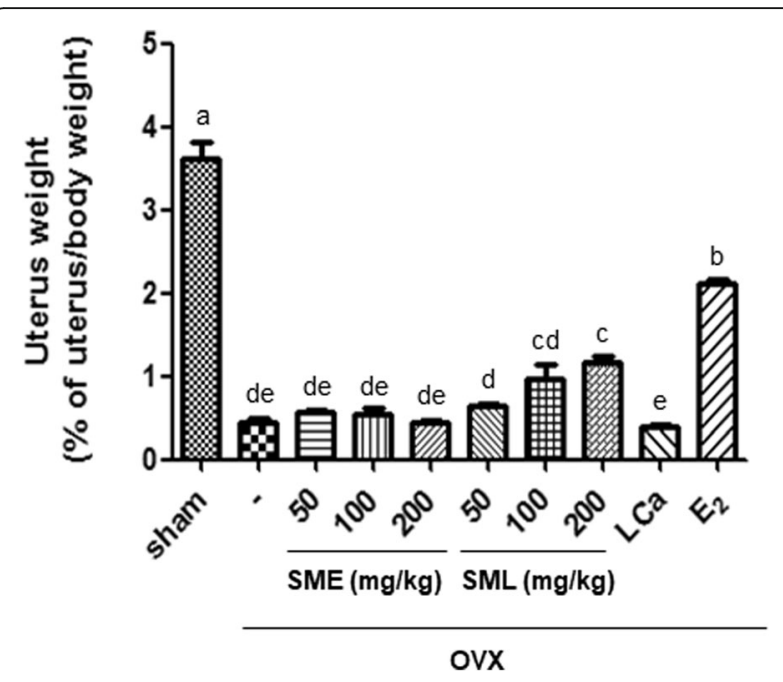

Fig. 1 Effects of SML on body weight and uterus weight in OVX mice. The uterus weights were collected at the conclusion of the study. Values are given as mean \pm S.E.M. of three independent experiments $(n=7)$ for all groups. Means unlike letters in a column with differ significantly $(p<0.05)$

\section{Effects of SML on the mechanical characteristics of trabecular bone}

Alteration of trabecular structure is mainly mediated in postmenopausal osteoporosis, and it relates to bone strength [39]. To investigate the effects of SML on trabecular bone structure, we estimated trabecular architectural parameters from 3D micro-CT images (Fig. 3a). In the OVX group, bone volume density (BV/TV, \%), trabecular thickness (Tb.Th, $\mathrm{mm}$ ), trabecular number (Tb.N, 1/mm), trabecular bone pattern factor (Tb.Pf, $\mathrm{mm}^{-1}$ ), bone surface/volume (BS/BV, $\left.1 / \mathrm{mm}\right)$, and bone mineral density (BMD, g/cm3) were significantly decreased (Fig. 3b-i). However, trabecular separation (Tb.Sp) and structure model index (SMI) were not altered compared to the other groups (Fig. 3d and h). Compared to the OVX group, BV/TV was significantly increased by SML administration in a dose-dependent manner (Fig. 3b). Tb.Th was only enhanced by oral administration of SML at $200 \mathrm{mg} / \mathrm{kg}$ (Fig. 3c). Tb.N was remarkably increased by SML in a dose-dependent manner, and in the $\mathrm{E}_{2}$-treated group (Fig. 3e). Tb.Pf and BS/ $\mathrm{BV}$ were significantly increased by oral administration in the SME group with $200 \mathrm{mg} / \mathrm{kg}$, in the SML group with $200 \mathrm{mg} / \mathrm{kg}$, in the LCa group, and in the $E_{2}$-treated group (Fig. 3f and g). In addition, BMD was reasonably restored in most groups (except on oral administration of SME at 100 or $200 \mathrm{mg} / \mathrm{kg}$ or of LCa) compared to the OVX group (Fig. 3i). However, Tb.Sp and SMI were significantly altered compared with the OVX group (Fig. 3d and h). Moreover, a high dose $(200 \mathrm{mg} / \mathrm{kg})$ of SML showed the most significant recovery effect on OVX- induced architectural deterioration of the trabecular bone.

\section{Effects of SML on serum biochemical markers in OVX mice}

To demonstrate the development of osteoporosis, the following markers were suggested: RANKL, OPG, osteocalcin, BALP, and $17 \beta$-estradiol $\left(\mathrm{E}_{2}\right)$. In addition, we investigated the inhibitory effects of SML on bone resorption-related serum markers in OVX mice. The balance between RANKL and OPG during osteoporosis is important for osteoclast regulation. This present study examined serum levels of RANKL and OPG using ELISA. In the OVX group, the serum level of RANKL was significantly increased (Fig. 4a), but OPG was suppressed compared to the sham group (Fig. 4b). Oral administration of SML at 100 and $200 \mathrm{mg} / \mathrm{kg}$ markedly decreased RANKL level compared to the OVX group (Fig. 4a). In contrast, OPG serum level significantly increased in the SML group at $200 \mathrm{mg} / \mathrm{kg}$ (Fig. 4b). The RANKL/OPG ratio was highly reduced compared to the OVX group (Fig. 4c). Moreover, $\mathrm{E}_{2}$ treatment significantly affected the increased serum level of OPG via inhibition of RANKL, while LCa administration did not have any effect on RANKL or OPG level compared to the OVX group. We next investigated whether SME and SML play a similar role to estrogen in OVX mice. As shown in Fig. $4 d$, the $17 \beta$-estradiol serum level was increased by SML at $200 \mathrm{mg} / \mathrm{kg}$.

\section{Effects of SML on serum levels of osteocalcin and BALP in OVX mice}

To evaluate the effects of SML on bone turnover in OVX mice, we measured the serum levels of osteocalcin and BALP by ELISA. OVX significantly increased osteocalcin level compared to the sham group. Oral administration of SME at 100 or $200 \mathrm{mg} / \mathrm{kg}$ markedly inhibited osteocalcin level (Fig. 4e). Bone alkaline phosphatase (BALP) is synthesized by osteoblasts and is presumed to be involved in the calcification of bone matrix [40]. We examined whether SML regulate BALP level using ELISA. As shown in Fig. 4f, oral administration of SME at $200 \mathrm{mg} / \mathrm{kg}$, of SML at 100 or $200 \mathrm{mg} / \mathrm{kg}$, of LCa, and of $E_{2}$ suppressed the production of BALP, suggesting an effect of SML on inhibition of bone turnover and calcification of bone matrix.

\section{Effects of SML on the expression of cathepsin $\mathrm{K}$ and calcitonin receptor (CalcR) in OVX mice}

Cathepsin $\mathrm{K}$ has been reported to be a cysteine protease involved in the bone remodeling and resorption related to osteoporosis [41]. In addition, calcitonin receptor is expressed during osteoclast differentiation to osteoblast [42]. To determine whether SML regulate bone resorption 


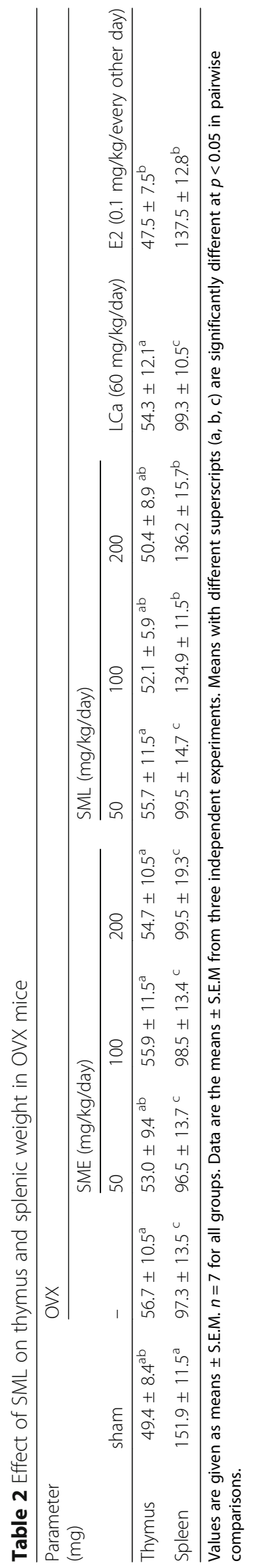




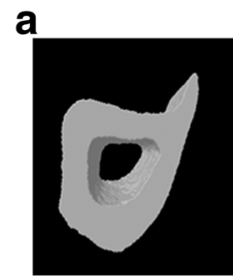

Sham

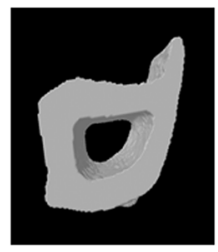

OVX + SML $50 \mathrm{mg} / \mathrm{kg}$

b

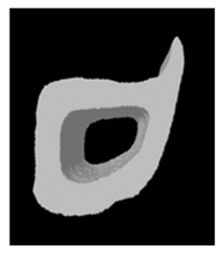

ovX

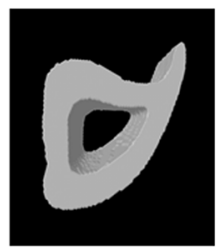

OVX + SML $100 \mathrm{mg} / \mathrm{kg}$

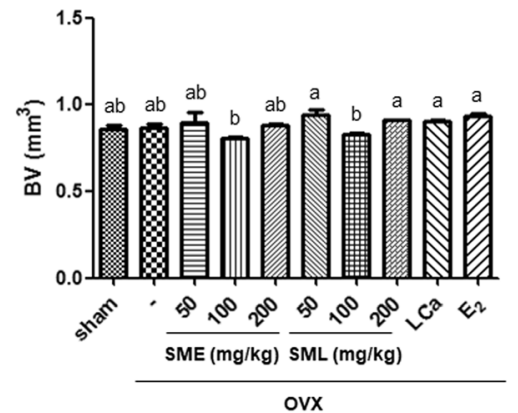

d

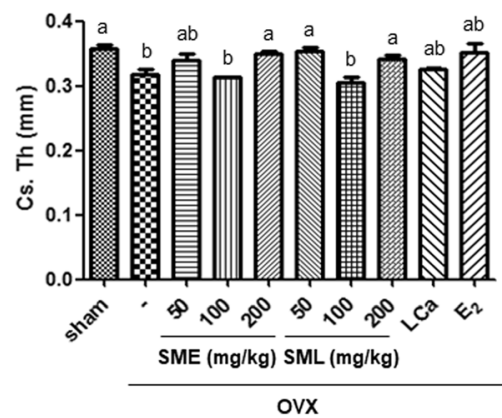

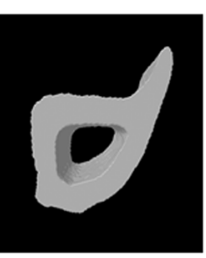

OVX + SME $50 \mathrm{mg} / \mathrm{kg}$

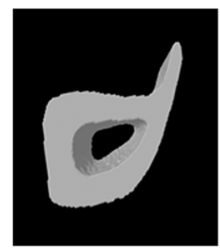

OVX + SML $200 \mathrm{mg} / \mathrm{kg}$

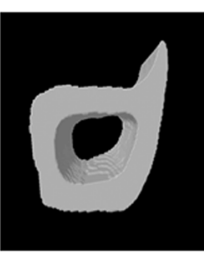

OVX + SME $100 \mathrm{mg} / \mathrm{kg}$

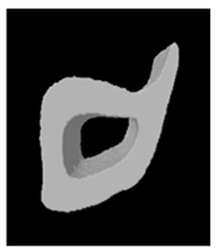

OVX + LCa $10 \mathrm{ml} / \mathrm{kg}$

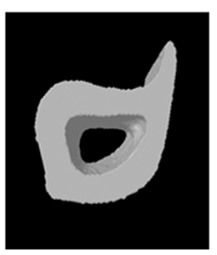

OVX + SME $200 \mathrm{mg} / \mathrm{kg}$

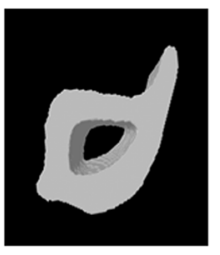

$\mathrm{OVX}+\mathrm{E}_{2} 0.1 \mathrm{mg} / \mathrm{kg}$

C

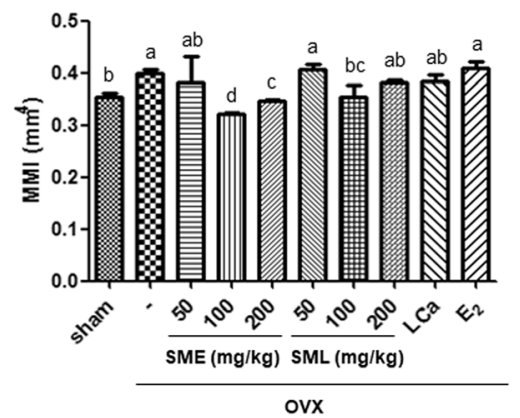

e

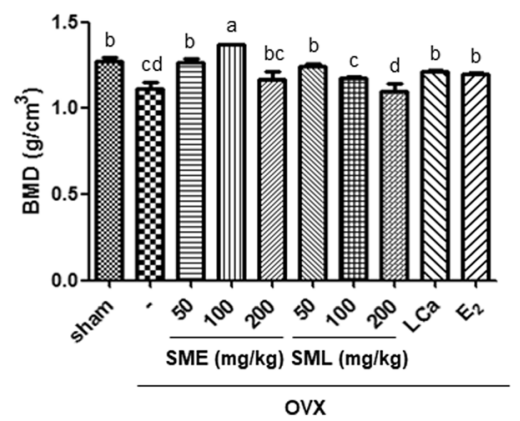

Fig. 2 Effects of SML on the structural characteristics of cortical bone. a Three-dimensional micro-CT images of cortical bone after 12 weeks in OVX mice. The cortical bone parameters were measured by a three-dimensional micro-CT analysis program. The measured cortical bone parameters were b bone volume density (BV, $\mathrm{mm}^{3}$ ), $\mathbf{c}$ mean polar moment of inertia (MMl, $\mathrm{mm}^{4}$ ), $\mathbf{d}$ cross-section thickness (Cs.Th, mm), and e bone mineral density $\left(B M D, g / \mathrm{cm}^{3}\right)$. Values are given as the mean \pm S.E.M. of three independent experiments $(n=7)$ for all groups. Means unlike letters in a column with differ significantly $(p<0.05)$

activity via the attenuation of osteoclast differentiation, we investigated the expression of the osteoclast-specific markers cathepsin $\mathrm{K}$ and CalcR in bone marrow cells derived from OVX mice. The mRNA expression of cathep$\sin \mathrm{K}$ and CalcR was significantly increased in the OVX group compared to the sham group. However, oral administration of the highest doses of SME and SML and $E_{2}$ treatment significantly inhibited the OVX-induced expression of cathepsin K and CalcR (Fig. 5a and b).
Effects of SML on the expression of TRAF6 and NFATc1 in OVX mice

To examine the molecular mechanism underlying the inhibitory effects of SML on osteoclast differentiation, we tested osteoclast differentiation-related signaling molecules. In the bone marrow cells of the OVX group, the mRNA expression of TRAF6 and NFATc was robust. Oral administration of SME at 100 or $200 \mathrm{mg} / \mathrm{kg}$ and SML in a dose-dependent manner significantly inhibited 


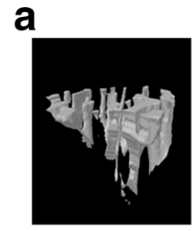

Sham

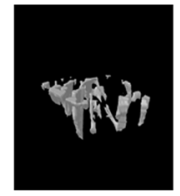

OVX + SML $50 \mathrm{mg} / \mathrm{kg} \quad$ OVX + SML $100 \mathrm{mg} / \mathrm{kg}$

b

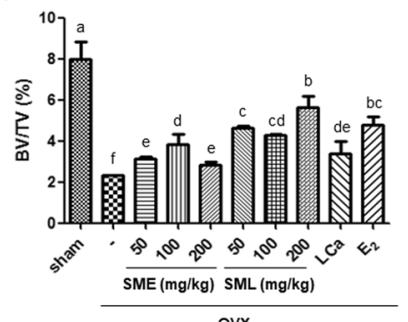

d

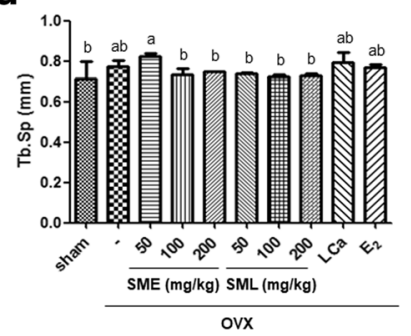

f

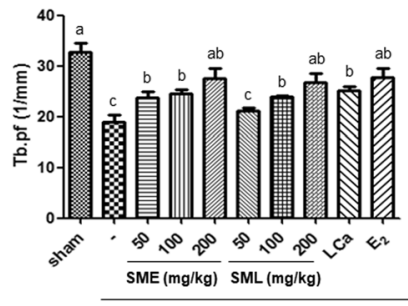

h

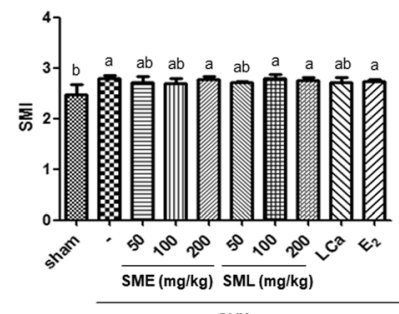

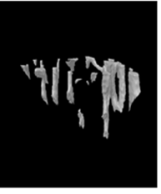
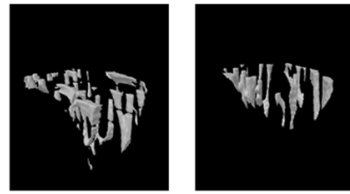

OVX + SME $50 \mathrm{mg} / \mathrm{kg}$

OVX + SME $100 \mathrm{mg} / \mathrm{kg}$

OVX + SME $200 \mathrm{mg} / \mathrm{kg}$
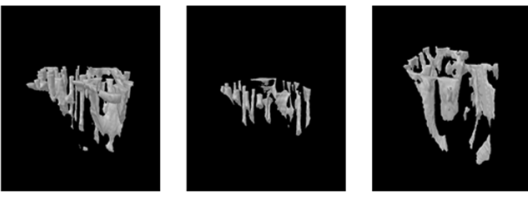

OVX + LCa $10 \mathrm{ml} / \mathrm{kg}$

$\mathrm{OVX}+\mathrm{E}_{2} 0.1 \mathrm{mg} / \mathrm{kg}$

C

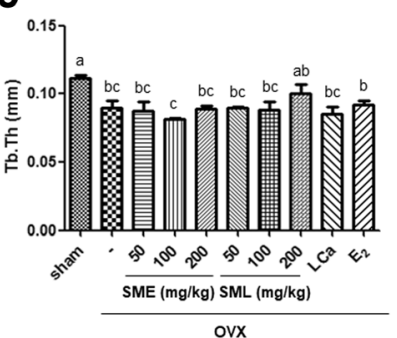

e

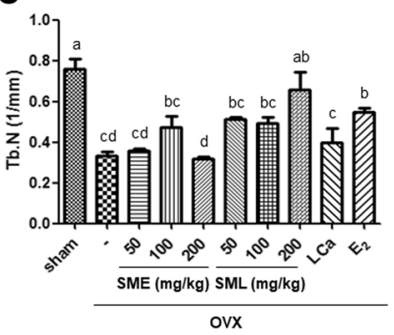

g

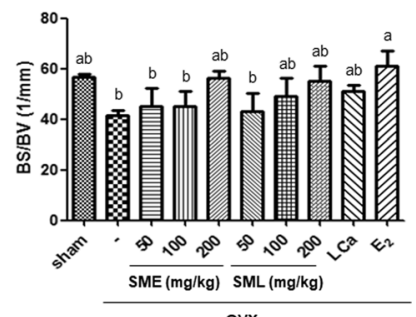

i

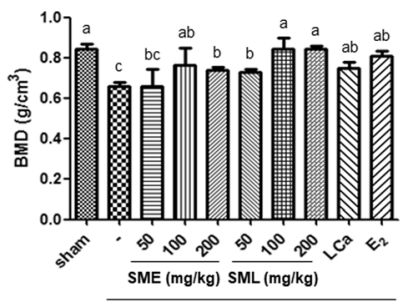

Fig. 3 (See legend on next page.) 
(See figure on previous page.)

Fig. 3 Effects of SML on the mechanical characteristics of trabecular bone. a Three-dimensional micro-CT images of trabecular bone after 12 weeks in OVX mice. The trabecular bone parameters were monitored by a three-dimensional micro-CT analysis program. The measured trabecular bone parameters were $\mathbf{b}$ bone volume fraction (BV/TV), $\mathbf{c}$ trabecular thickness (Tb.Th), $\mathbf{d}$ trabecular separation (Tb.Sp), e trabecular number (Tb.N), $\mathbf{f}$ trabecular bone pattern factor (Tb.Pf), $\mathbf{g}$ specific bone surface (BS/BV), $\mathbf{h}$ structure model index (SMI), and $\mathbf{i}$ bone mineral density (BMD). Values are given as mean \pm S.E.M. of three independent experiments $(n=7)$ for all groups. Means unlike letters in a column with differ significantly $(p<0.05)$

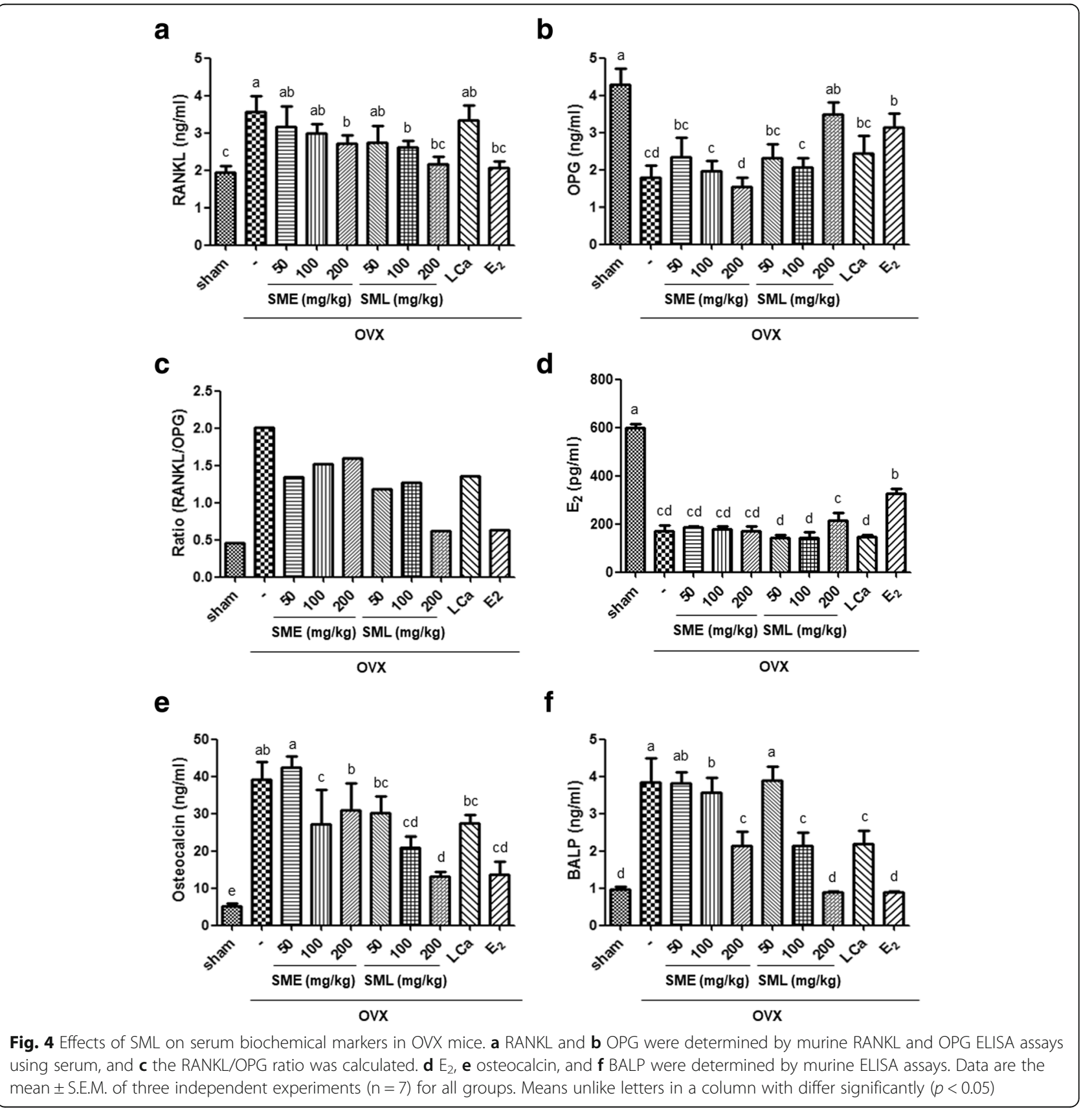



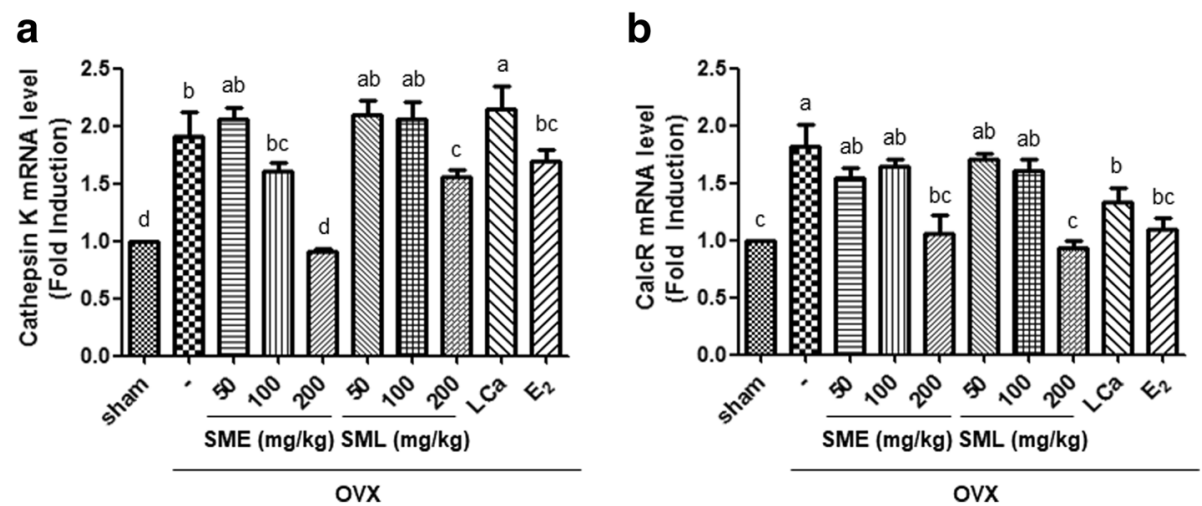

Fig. 5 Effects of SML on the expression of cathepsin $\mathrm{K}$ and calcitonin receptor (CalcR) in OVX mice. RNA was extracted from the bone marrow cells of OVX mice, and $\mathbf{a}$ the mRNA levels of cathepsin $\mathrm{K}$ and $\mathbf{b}$ calcitonin receptor were assessed by real-time PCR assay. $\beta$-actin was considered an internal control. Data are the mean \pm S.E.M. of three independent experiments $(n=7)$ for all groups. Means unlike letters in a column with differ significantly $(p<0.05)$

OVX-induced TRAF6 mRNA expression (Fig. 6a). In addition, OVX-induced NFATc expression was markedly attenuated by SML in a dose-dependent manner (Fig. $6 b)$.

\section{Discussion}

Salvia miltiorrhiza Bunge has been shown to have anticancer, antioxidant, and anti-inflammatory activities [43-45]. In addition, the ethanol extract of Salvia miltiorrhiza Bunge has played a role as an anti-osteoporotic agent [46]. In this study, we demonstrated that administration of SML, a combination of aqueous extract of $S$. miltiorrhiza Bunge (SME) and liquefied calcium supplement (LCa), inhibited OVX-induced osteoporosis. SML administration showed an increase of BV/TV consistent with an improvement in the BMD of trabecular bone, suggesting that it can prevent the loss of bone mass induced by OVX. In addition, Tb.N related to trabecular connectivity was restored in a dose-dependent manner by SML. Moreover, the BS/BV and Tb.Pf decreased by OVX were increased by SML administration. However, SML did not affect Tb.Sp and SMI in trabecular bone. In the cortical compartment analysis, supplementation with SML did not affect BV, MMI, Cs.Th, or BMD. We also examined the combined effects of SME and LCa on OVX-induced osteoporosis. Although administration of SME at $200 \mathrm{mg} / \mathrm{kg}$ without $\mathrm{LCa}$ had a mild antiosteoporotic effect, it did not compare to that of SML. The comparison between LCa sole administration and LCa combined with SME showed that SME may have a synergistic effect on LCa supplementation, enhancing bone metabolism.

It has been reported that the main constituents of $S$. miltiorrhiza include tanshinones, salvianolic acid B, and
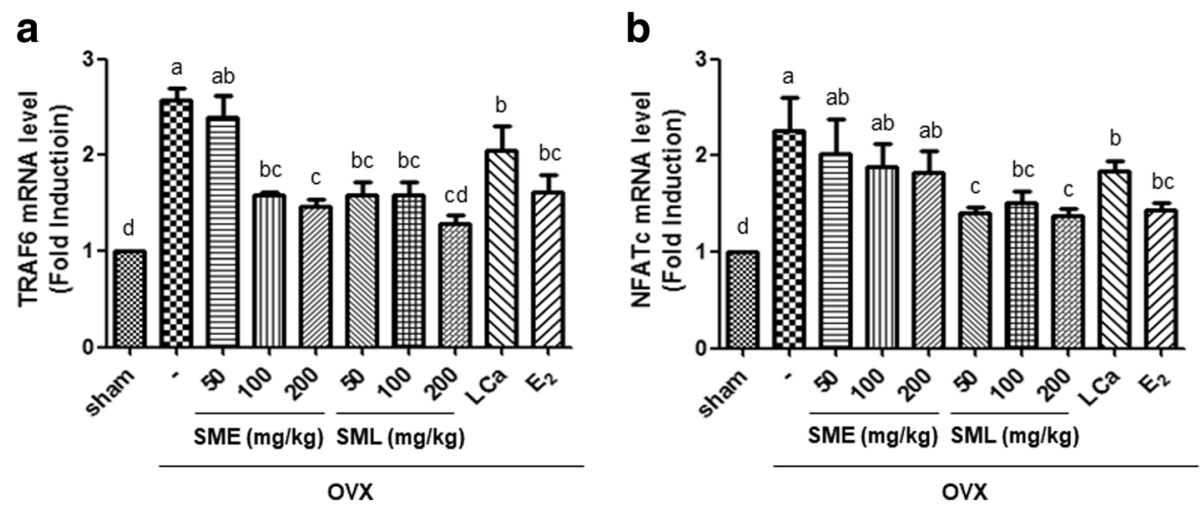

Fig. 6 Effects of SML on the expression of TRAF6 and NFATc1 in OVX mice. RNA was extracted from the bone marrow cells of OVX mice, and $\mathbf{a}$ the mRNA levels of TRAF6 and $\mathbf{b}$ NFATC1 were assessed by real-time PCR assay. $\beta$-actin was considered an internal control. Data are the mean \pm S.E.M. of three independent experiments $(n=7)$ for all groups. Means unlike letters in a column with differ significantly $(p<0.05)$ 
danshensu [27]. In 2004, Kim et al. demonstrated that tanshinone IIA (known already as an antioxidant) inhibited bone resorption by attenuating the differentiation and activity of osteoclasts in vitro. In addition, it has been shown that tanshinone IIA, as a phytoestrogen, is capable of activating the estrogen receptor signaling pathway. This leads to increased endothelial nitric oxide synthase gene expression, increased nitric oxide production, and $\mathrm{Ca}^{2+}$ mobilization to treat cardiovascular disease [47]. Based on previous studies, phytoestrogens (such as tanshinone IIA) and isoflavones may directly interact with estrogen receptors in bone and affect bone metabolism [48, 49]. Therefore, it is possible that estrogen-like chemicals (such as the tanshinone IIA contained in S. miltiorrhiza) can improve intestinal Ca absorption through an estrogen-like mechanism. However, the mechanisms by which $S$. miltiorrhiza increases intestinal $\mathrm{Ca}$ absorption have not been elucidated, and further investigation is required.

Estrogen exerts its regulatory effects on gene expression in target tissues by different mechanisms. The uterus is one of the most estrogen-responsive reproductive tissues, and it predominantly expresses ER $\alpha$ [50-52]. In this study, OVX mice showed initial atrophy of the uterus, while the treatment with estradiol recovered the weight loss of the uterus. Moreover, it was found that SML administration at 100 or $200 \mathrm{mg} / \mathrm{kg}$ significantly increased the weight of the uterus. Even though $S$. miltiorrhiza Bunge combined with liquefied calcium supplement was announced to block bone loss in ovariectomized mice caused by estrogenic effect, there are some argument about whether the estrogenic effect on the gain of uterus weight might lead to develop a risk of endometrial cancer [46]. Our research could demonstrate that the administration of SML at the dose of $200 \mathrm{mg} / \mathrm{kg} \cdot$ body weight is non-toxic effect in the OVX mice. If it alters our animal experimental dose to human dose, this supplemental dose can be converted to $973.2 \mathrm{mg} /$ day for an adult having $60 \mathrm{~kg}$.body weight. Accordingly, it could comfortably be taken in extract form by human. Whereas, further research is certainly required for human to have benefit effect of S. miltiorrhiza Bunge on osteoporosis.

It has been announced that hematopoiesis is one of the main effects of deficient estrogen on the immune system [53]. Ovariectomy is reported to increase the thymic weight, contributing to increased thymic $\mathrm{T}$ cell output and exacerbating bone loss, whereas splenic weight is inhibited. Therefore, $\mathrm{E}_{2}$ treatment is known to regulate the weight of the thymus and the spleen [5456]. Our data supported these findings by showing an increase in the weight of the thymus in OVX mice, which was decreased by $E_{2}$. In addition, SML administration at 100 or $200 \mathrm{mg} / \mathrm{kg}$ inhibited the thymus weight by about $8.1 \%$ (or $11.1 \%$ ) in OVX mice. However, the decreased weight of the spleen in OVX mice was restored to about $27.8 \%$ (or $28.5 \%$ ) on administration of SML at 100 or $200 \mathrm{mg} / \mathrm{kg}$ compared to the OVX group. The present data indicated that the combination of SME and LCa could regulate the weight of thymus and spleen to inhibit OVX-increased immune cells to develop osteoporosis.

RANKL/OPG represent a pair of cross-talk regulators between osteoblasts and osteoclasts that together regulate osteoclastogenesis [57]. Overexpression of the OPG gene in mice led to high bone mass and significant reductions in osteoclast number and activity. Additionally, this has been observed in the non-lamellated bone of OPG knockout mice [58]. RANKL is a type II transmembrane protein that exists in both membrane-bound and soluble forms [59]. It has been reported that soluble and membrane-bound RANKL are biologically active in promoting osteoclast formation $[60,61]$. The pharmacological RANKL inhibition in OVX mice models, Therefore, using OPG-Fc administered immediately after the OVX procedure, was associated with increased bone volume and density and increased the biomechanical strength of the vertebrae and the femur neck sites that are prone to fragility fractures in women with postmenopausal osteoporosis [62]. In the present study, we demonstrated that SML significantly increased the levels of biochemical markers related to bone metabolism by increasing the production of OPG at the highest dose and attenuating the expression of RANKL in OVX mice. Moreover, osteocalcin as a bone turnover marker in serum is known to be up-regulated in osteoporosis and inhibited by estrogen [63]. Our study showed that OVXinduced osteocalcin level in serum was significantly reduced, but the decreased level of $\mathrm{E}_{2}$ caused by OVX was markedly increased (about 17\%) on SML administration at $200 \mathrm{mg} / \mathrm{kg}$ compared to the OVX group. As mentioned above, increased RANKL in OVX mice exerted osteoclast differentiation. To determine whether the combination of SME and LCa inhibit osteoclast differentiation, we investigated expression of the osteoclast differentiation markers cathepsin $\mathrm{K}$ and calcitonin receptor (CalcR) in bone marrow cells derived from OVX mice. In the present study, we showed that OVX-induced cathepsin $\mathrm{K}$ and calcitonin receptor were significantly inhibited on administration of SML at the highest dose.

Bone formation markers are direct or indirect products of osteoblasts in each phase of development. They reflect different aspects of osteoblast function and bone formation and are mostly measured in the blood. Alkaline phosphatase (ALP), one of the bone formation markers, is an enzyme that plays an important role in osteoid formation and calcification. In particular, bone alkaline phosphatase (BALP) is reported to be a widely available marker of metabolic bone diseases and is 
increased in the serum of postmenopausal women [64]. We demonstrated that oral administration of SME at $200 \mathrm{mg} / \mathrm{kg}$, SML at 100 or $200 \mathrm{mg} / \mathrm{kg}$, LCa sole administration, and $E_{2}$ treatment suppressed the production of BALP, suggesting that SML influenced on inhibition of bone turnover and calcification of bone matrix.

The ligation of RANK with RANKL results in trimerization of RANK and recruitment of adapter molecules such as the TNF receptor associated factor (TRAF) family of proteins, among which TRAF6 has been shown to be a major adapter molecule [65]. In addition, the TRAF6-mediated signaling complex has been reported to be implicated in the RANKL-stimulated activation of NFATc1, a major regulator of osteoclast-specific genes such as cathepsin $\mathrm{K}$, calcitonin receptor, tartrateresistant acid phosphatase (TRAP), osteoclast-associated receptor (OSCAR), and $\beta 3$ integrin; it is often accompanied by other transcription factors such as AP-1, PU.1, microphthalmia-associated transcription factor (MITF), and CREB during osteoclastogenesis [66, 67]. In this study, the increased mRNA expression of TRAF6 and NFATc1 in OVX mice was significantly attenuated by administration of SML at the highest doses. Moreover, SML administration inhibited the mRNA expression of TRAF6 and NFATc1 in the RANK signaling pathway and inhibited the expression of cathepsin $\mathrm{K}$ and calcitonin receptor, leading to the inhibition of osteoclast differentiation.

Estrogen deficiency induces TNF- $\alpha$ secretion by T cells through a complex pathway involving the thymus and bone marrow. TNF- $\alpha$ upregulates osteoclast formation by increasing stromal cell production of RANKL and MCSF $[68,69]$. This situation induces an imbalance between RANKL and OPG. Additionally, it is critical in the occurrence of postmenopausal bone loss [70]. Many studies have also reported that reactive oxygen species (ROS) may play a role in postmenopausal bone loss by creating a more oxidized bone microenvironment [71]. S. miltiorrhiza contains many constituents such as tanshinones, salvianolic acid B, and danshensu, all of which have antioxidant activity to reduce ROS. Tanshinone IIA plays the role of a phytoestrogen in upregulating ER signaling pathways. In the present study, we demonstrated that an aqueous extract of $S$. miltiorrhiza (SME) or liquefied calcium supplement (LCa) had a partial antiosteoporosis effect in OVX mice. However, a combination (SML) of SME and LCa had a synergistic activity that may be useful to treat osteoporosis.

\section{Conclusion}

In conclusion, these data suggest that SML has the protective effect on estrogen-deficient bone loss through blocking the RANKL signaling pathway-induced expression of TRAF6 and NFTAc1 as well as the upregulated cathepsin $\mathrm{K}$ and calcitonin receptor to promote osteoclast differentiation (Fig. 7). The inhibitory activity of SML in OVX mice implies the possibility of a pharmacological intervention specifically directed toward a disease like osteoporosis, where decreased bone strength increases the risk of a broken bone.

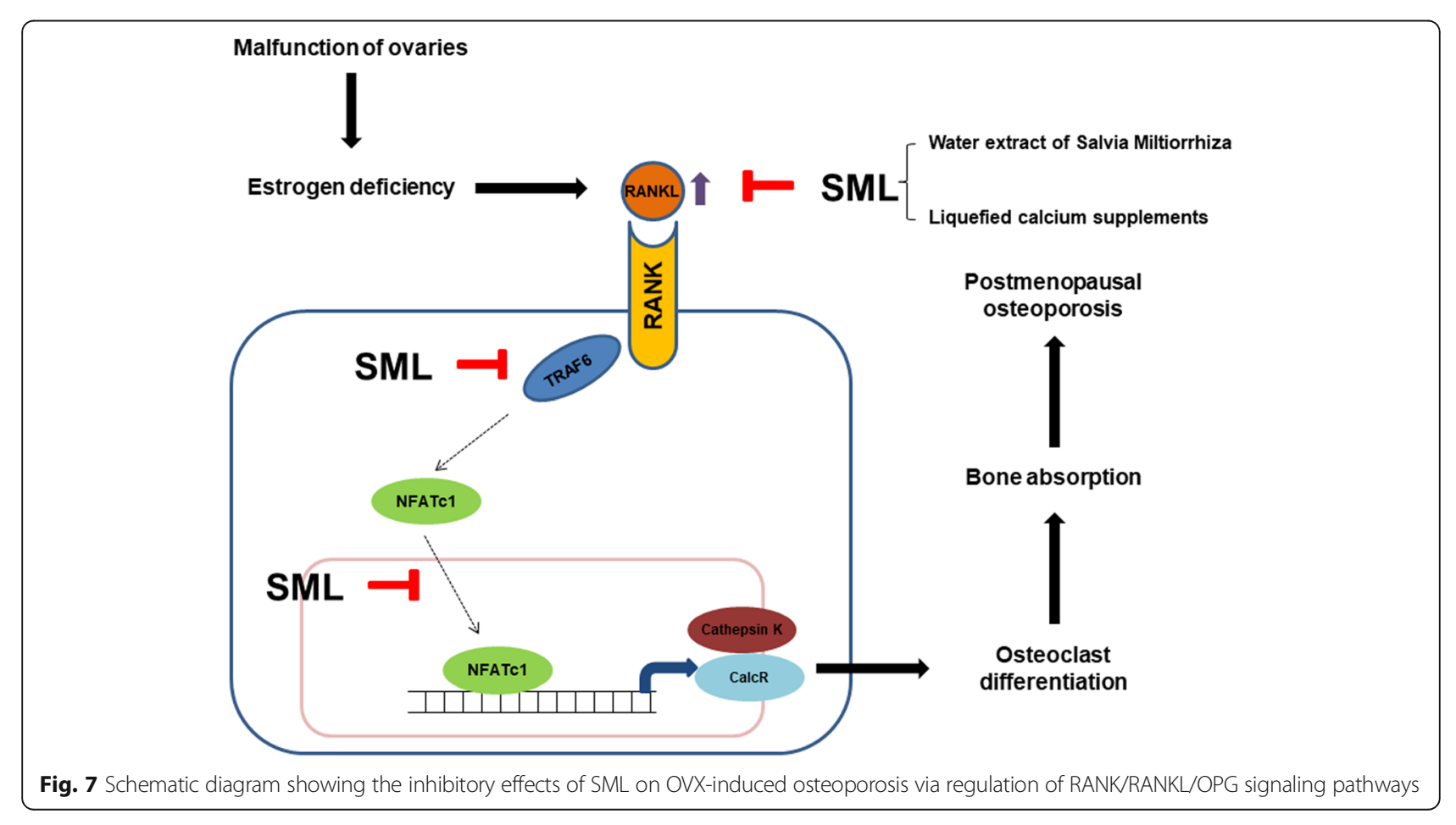




\section{Additional file}

Additional file 1: Figure S1. HPLC analysis of SME and standards of Salvianolic acid. (a) HPLC chromatogram of water extract of Salvia miltorrhiza Bunge at $280 \mathrm{~nm}$ (b) HPLC results of standard salvianolic acid from the Salvia miltorrhiza Bunge (DOCX $25 \mathrm{~kb}$ )

\section{Abbreviations}

BALP: Bone alkaline phosphatase; BMD: Bone volume fraction; BS/BV: Specific bone surface; BV: Bone volume fraction; BV/TV: Bone volume fraction; CalcR: Calcitonin receptor; cathepsin K: calcitonin receptor; $C$. Th: cross section thickness; E2: 17ß-estradiol; HRT: Hormone replacement therapy; LCa: Liquefied calcium; MITF: Microphthalmia-associated transcription factor; MMI: Mean polar moment of inertia; NFTAc1: Nuclear factor of activated Tcells, cytoplasmic 1; OPG: Osteoprotegerin; OSCAR: Osteoclast-associated receptor; OVX: Ovariectomized; RANKL: Receptor activator of nuclear factor kappa-B ligand; ROS: Reactive oxygen species; SME: Ethanol extract of S. miltiorrhiza Bunge; SMI: Structure model index; SML: Combination of SME and LCa; Tb.N: Trabecular number; Tb.Pf: Trabecular bone pattern factor; Tb.Sp: Trabecular separation; Tb.Th: Trabecular thickness; TLC: Thin layer chromatography; TRAF6: TNF receptor associated factor 6; TRAP: Tartrateresistant acid phosphatase

\section{Acknowledgements}

We sincerely appreciate other colleagues in our laboratory for their help and effort in this study.

\section{Funding}

This work was supported by the Food Functionality Evaluation Program under the Ministry of Agriculture, Food, and Rural Affairs, by the Korea Food Research Institute, and by a grant from Kyung Hee University (KHU-20160597).

\section{Availability of data and materials}

All relevant data generated or analyzed during this study are included in this published article.

\section{Authors' contributions}

BP: made significant contributions to the design of the study as well as the interpretation and analysis of the data, write manuscript, HSS, JEK,SMC and SAJ: made important contributions to the design of the study, the collection of data as well as the interpretation and analysis of the data, MYK: made important contributions to the design of the study, collected and performed the analysis of the data, SCK: revised the manuscript critically, and gave final approval of the version to be published. All authors read and approved the final manuscript.

\section{Authors' information}

$\mathrm{BP}$ is a research professor in Department of Oriental Medicine Biotechnology, Kyung Hee University.

HSS, JEK, SMC and SAJ are a graduate student in Department of Oriental Medicine Biotechnology, Kyung Hee University and is supervised by SCK. MYK is a senior researcher in KMF corp.

SCK is a professor in in Department of Oriental Medicine Biotechnology, Kyung Hee University

\section{Ethics approval}

The Experimental Animal Facility and protocols were approved by the Institutional Animal Care and Use Committee of Kyung Hee University.

\section{Consent for publication}

Not applicable

\section{Competing interests}

The authors declare that they have no competing interests.

\section{Publisher's Note}

Springer Nature remains neutral with regard to jurisdictional claims in published maps and institutional affiliations.

\section{Author details}

'Department of Oriental Medicine and Biotechnology, College of Life Science, Kyung Hee University, Yongin-si 17104, Republic of Korea. ${ }^{2}$ KMF Co., Ltd., Yulam-ro 12, Dong-gu, Daegu-si 41065, Republic of Korea.

Received: 22 September 2017 Accepted: 6 December 2017

Published online: 20 December 2017

\section{References}

1. Farrokhi S, Tashman S, Gil AB, Klatt BA, Fitzgerald GK. Are the kinematics of the knee joint altered during the loading response phase of gait in individuals with concurrent knee osteoarthritis and complaints of joint instability? A dynamic stereo X-ray study. Clin Biomech. 2012;27(4):384-9.

2. Rachner TD, Khosla S, Hofbauer LC. Osteoporosis: now and the future. Lancet. 2011;377(9773):1276-87.

3. Roman-Blas JA, Castañeda S, Largo R, Herrero-Beaumont G. Osteoarthritis associated with estrogen deficiency. Arthritis research \& therapy. 2009;11(5):1.

4. Fraser L-A, Vogt KN, Adachi JD, Thabane L. Fracture risk associated with continuation versus discontinuation of bisphosphonates after 5 years of therapy in patients with primary osteoporosis: a systematic review and meta-analysis. Ther Clin Risk Manag. 2011;7:157-66.

5. Koo HJ, Sohn E-H, Kim Y-J, Jang S-A, Namkoong S, Kang SC. Effect of the combinatory mixture of Rubus Coreanus Miquel and Astragalus Membranaceus Bunge extracts on ovariectomy-induced osteoporosis in mice and anti-RANK signaling effect. J Ethnopharmacol. 2014;151(2):951-9.

6. Abuohashish HM, Ahmed MM, Al-Rejaie SS, Eltahir KE. The antidepressant bupropion exerts alleviating properties in an ovariectomized osteoporotic rat model. Acta Pharmacol Sin. 2015;36(2):209.

7. Thompson D, Simmons H, Pirie C, Ke H. FDA Guidelines and animal models for osteoporosis. Bone. 1995;17(4):S125-33.

8. Abukhadir S S, Mohamed N, Mohamed N. Pathogenesis of alcohol-induced osteoporosis and its treatment: a review. Curr Drug Targets. 2013;14(13): 1601-10.

9. You L, Sheng Z-Y, Tang C, Chen L, Pan L, Chen J-Y. High cholesterol diet increases osteoporosis risk via inhibiting bone formation in rats. Acta Pharmacol Sin. 2011;32(12):1498.

10. Seto H, Aoki K, Kasugai S, Ohya K. Trabecular bone turnover, bone marrow cell development, and gene expression of bone matrix proteins after low calcium feeding in rats. Bone. 1999:25(6):687-95.

11. Abuohashish HM, Al-Rejaie SS, Al-Hosaini KA, Parmar MY, Ahmed MM. Alleviating effects of morin against experimentally-induced diabetic osteopenia. Diabetology \& metabolic syndrome. 2013;5(1):5.

12. Li B, Wang Y, Liu Y, Ma J, Li Y. Altered gene expression involved in insulin signaling pathway in type II diabetic osteoporosis rats model. Endocrine. 2013;43(1):136-46.

13. Kelly P: Is osteoporosis a genetically determined disease? $\mathrm{Br} J$ Obstet Gynaecol 1996, 103:20-26; discussion 26-27.

14. Pacifici R. Editorial: cytokines, estrogen, and postmenopausal osteoporosis — the second decade. Endocrinology. 1998;139(6):2659-61.

15. Kearns AE, Khosla S, Kostenuik PJ. Receptor activator of nuclear factor $\mathrm{KB}$ ligand and osteoprotegerin regulation of bone remodeling in health and disease. Endocr Rev. 2008;29(2):155-92.

16. Flynn A. The role of dietary calcium in bone health. Proceedings of the Nutrition Society. 2003:62(04):851-8.

17. Kang S-C, Kim HJ, Kim M-H. Effects of Astragalus Membranaceus with supplemental calcium on bone mineral density and bone metabolism in calcium-deficient ovariectomized rats. Biol Trace Elem Res. 2013;151(1):68-74.

18. Marsden J. The menopause, hormone replacement therapy and breast cancer. J Steroid Biochem Mol Biol. 2002;83(1):123-32.

19. Reid IR. Pharmacotherapy of osteoporosis in postmenopausal women: focus on safety. Expert Opin Drug Saf. 2002;1(1):93-107.

20. Yeh I-T. Postmenopausal hormone replacement therapy: endometrial and breast effects. Adv Anat Pathol. 2007:14(1):17-24.

21. Miksicek RJ. Interaction of naturally occurring nonsteroidal estrogens with expressed recombinant human estrogen receptor. J Steroid Biochem Mol Biol. 1994:49(2):153-60

22. Breitman $\mathrm{PL}$, Fonseca D, Cheung AM, Ward WE. Isoflavones with supplemental calcium provide greater protection against the loss of bone mass and strength after ovariectomy compared to isoflavones alone. Bone. 2003;33(4):597-605. 
23. Huangb MW, Zhuc Y-C, Linzd W, Duanb W, Zhua Y-Z. Effects of salvia miltiorrhiza after acute myocardial infarction in rats. Novel Compounds from Natural Products in the New Millennium: Potential and Challenges. 2004;183

24. Kim SY, Moon TC, Chang HW, Son KH, Kang SS, Kim HP. Effects of tanshinone I isolated from salvia miltiorrhiza bunge on arachidonic acid metabolism and in vivo inflammatory responses. Phytother Res. 2002;16(7): $616-20$

25. Y-J W, Hong C-Y, Lin S-J, Wu P, Shiao M-S. Increase of vitamin E content in $\mathrm{LDL}$ and reduction of atherosclerosis in cholesterol-fed rabbits by a watersoluble antioxidant-rich fraction of salvia miltiorrhiza. Arterioscler Thromb Vasc Biol. 1998;18(3):481-6.

26. Guo Y, Li Y, Xue L, Severino RP, Gao S, Niu J, Qin L-P, Zhang D, Brömme D. Salvia miltiorrhiza: an ancient Chinese herbal medicine as a source for antiosteoporotic drugs. J Ethnopharmacol. 2014;155(3):1401-16.

27. Liu H, Wang X, Wang D, Zou Z, Liang Z. Effect of drought stress on growth and accumulation of active constituents in salvia miltiorrhiza Bunge. Ind Crop Prod. 2011;33(1):84-8.

28. Kim H-H, Kim JH, Kwak HB, Huang H, Han S-H, Ha H, Lee SW, Woo E-R, Lee $\mathrm{ZH}$. Inhibition of osteoclast differentiation and bone resorption by tanshinone IIA isolated from salvia miltiorrhiza Bunge. Biochem Pharmacol. 2004;67(9):1647-56.

29. Cao E-H, Liu X-Q, Wang J-J, N-F X. Effect of natural antioxidant tanshinone I-A on DNA damage by lipid peroxidation in liver cells. Free Radic Biol Med. 1996;20(6):801-6.

30. Chen $\mathrm{Y}-\mathrm{H}, \mathrm{G}-\mathrm{H}$ D, Zhang J-T. Salvianolic acid B protects brain against injuries caused by ischemia-reperfusion in rats. Acta Pharmacol Sin. 2000;21(5):463-6.

31. G-H D, Qiu Y, Zhang J-T. Salvianolic acid B protects the memory functions against transient cerebral ischemia in mice. J Asian Nat Prod Res. 2000;2(2): $145-52$.

32. Jang S-Y, Jeong Y-J, Kwon T-K, Seo J-H. Effects of water-soluble calcium supplements made from eggshells and oyster shells on the calcium metabolism of growing rats. Journal of Food Science and Nutrition. 2010; 15(1):78-82.

33. Heaney RP, Dowell MS, Bierman J, Hale CA, Bendich A. Absorbability and cost effectiveness in calcium supplementation. J Am Coll Nutr. 2001;20(3): 239-46.

34. Hanzlik RP, Fowler SC, Fisher DH. Relative bioavailability of calcium from calcium formate, calcium citrate, and calcium carbonate. J Pharmacol Exp Ther. 2005;313(3):1217-22.

35. Jang S-Y, Jeong Y-J, Kwon T-K, Seo J-H, Park E-M. The effect of water-soluble calcium supplements on calcium metabolism and bone metabolism of growing rats. Preventive Nutrition and Food Science. 2007;12(4):217-21.

36. Jeong Y, Kim J, Kim G. Effects of liquefied calcium supplement on bone mineral density in middle-aged women. Journal of the Korean Society of Food Science and Nutrition. 2004;

37. Jang $\mathrm{S}-\mathrm{Y}$, Baek $\mathrm{C}-\mathrm{H}$, Jeong $\mathrm{K}-\mathrm{H}$, Park $\mathrm{N}-\mathrm{Y}$, Jeong $\mathrm{Y}$-J. Effect of vinegar on the solubility of calcium. Korean Journal of Food Preservation. 2005; 12(2):112-6.

38. Judex S, Luu Y, Ozcivici E, Adler B, Lublinsky S, Rubin C. Quantification of adiposity in small rodents using micro-CT. Methods. 2010;50(1):14-9.

39. Yeh $\mathrm{O}$, Keaveny $\mathrm{T}$. Biomechanical effects of intraspecimen variations in trabecular architecture: a three-dimensional finite element study. Bone. 1999;25(2):223-8.

40. Roudsari JM, Mahjoub S. Quantification and comparison of bone-specific alkaline phosphatase with two methods in normal and paget's specimens. Caspian journal of internal medicine. 2012;3(3):478.

41. Leung P, Pickarski M, Zhuo $Y$, Masarachia P, Duong $L$. The effects of the cathepsin $\mathrm{K}$ inhibitor odanacatib on osteoclastic bone resorption and vesicular trafficking. Bone. 2011;49(4):623-35.

42. Dacquin R, Davey RA, Laplace C, Levasseur R, Morris HA, Goldring SR, GebreMedhin S, Galson DL, Zajac JD, Karsenty G. Amylin inhibits bone resorption while the calcitonin receptor controls bone formation in vivo. J Cell Biol. 2004;164(4):509-14.

43. Chen X, Guo J, Bao J, Lu J, Wang Y. The anticancer properties of salvia miltiorrhiza Bunge (Danshen): a systematic review. Med Res Rev. 2014;34(4): 768-94

44. Wu W, Zhu Y, Zhang L, Yang R, Zhou Y. Extraction, preliminary structural characterization, and antioxidant activities of polysaccharides from salvia miltiorrhiza Bunge. Carbohydr Polym. 2012;87(2):1348-53.

45. Li M, Zhang L, Cai RL, Gao Y, Qi Y. Lipid-soluble extracts from salvia miltiorrhiza inhibit production of LPS-induced inflammatory mediators via
NF-kB modulation in RAW 264.7 cells and perform Antiinflammatory effects in vivo. Phytother Res. 2012;26(8):1195-204.

46. Cui Y, Bhandary B, Marahatta A, Lee G-H, Li B, Kim D-S, Chae S-W, Kim H-R, Chae $\mathrm{H}$-J: Characterization of salvia Miltiorrhiza ethanol extract as an antiosteoporotic agent. BMC Complement Altern Med 2011, 11(1):1.

47. Fan $G$, Zhu Y, Guo H, Wang X, Wang H, Gao X. Direct vasorelaxation by a novel phytoestrogen tanshinone $\| \mathrm{A}$ is mediated by nongenomic action of estrogen receptor through endothelial nitric oxide synthase activation and calcium mobilization. J Cardiovasc Pharmacol. 2011;57(3):340-7.

48. Kuiper GG, Carlsson B, Grandien K, Enmark E, Haggblad J, Nilsson S, Gustafsson J-A. Comparison of the ligand binding specificity and transcript tissue distribution of estrogen receptors a and $\beta$. Endocrinology. 1997; 138(3):863-70.

49. Onoe $Y$, Miyaura C, Ohta H, Nozawa S, Suda T. Expression of estrogen receptor $\beta$ in rat bone. Endocrinology. 1997;138(10):4509-12.

50. Couse JF, Lindzey J, Grandien K, AK GJ, Korach KS. Tissue distribution and quantitative analysis of estrogen receptor- $\alpha(E R a)$ and estrogen receptor- $\beta$ $(E R \beta)$ messenger ribonucleic acid in the wild-type and ERa-knockout mouse. Endocrinology. 1997;138(11):4613-21.

51. Nilsson S, Mäkelä S, Treuter E, Tujague M, Thomsen J, Andersson G, Enmark E, Pettersson K, Warner M, Gustafsson J-Å. Mechanisms of estrogen action. Physiol Rev. 2001;81(4):1535-65.

52. Winuthayanon W, Piyachaturawat $P$, Suksamrarn A, Burns KA, Arao Y, Hewitt SC, Pedersen LC, Korach KS. The natural estrogenic compound diarylheptanoid (D3): in vitro mechanisms of action and in vivo uterine responses via estrogen receptor [alpha]. Environmental Health Perspectives (Online). 2013;121(4):433.

53. Andreoli T, Bennett J, Carpenter C, Plum F. Compendio de Medicina Interna Cecil. In: EEUU: Me Graw-Hill Interamericana. 1997;

54. Erlandsson M, Jonsson C, Lindberg MK, Ohlsson C, Carlsten H. Raloxifeneand estradiol-mediated effects on uterus, bone and B lymphocytes in mice. J Endocrinol. 2002;175(2):319-27.

55. Puel C, Mathey J, Agalias A, Kati-coulibaly S, Mardon J, Obled C, Davicco M-J, Lebecque P, Horcajada M-N, Skaltsounis AL. Dose-response study of effect of oleuropein, an olive oil polyphenol, in an ovariectomy/inflammation experimental model of bone loss in the rat. Clin Nutr. 2006;25(5):859-68.

56. Yellayi S, Naaz A, Szewczykowski MA, Sato T, Woods JA, Chang J, Segre M, Allred CD, Helferich WG, Cooke PS. The phytoestrogen genistein induces thymic and immune changes: a human health concern? Proc Natl Acad Sci. 2002;99(11):7616-21.

57. Aubin JE, Bonnelye E. Osteoprotegerin and its ligand: a new paradigm for regulation of osteoclastogenesis and bone resorption. Osteoporos Int. 2000; 11(11):905-13.

58. Xie H, Xie P-L, X-P W, Chen S-M, Zhou H-D, Yuan L-Q, Sheng Z-F, Tang S-Y, Luo X-H, Liao E-Y. Omentin-1 attenuates arterial calcification and bone loss in osteoprotegerin-deficient mice by inhibition of RANKL expression. Cardiovasc Res. 2011;92(2):296-306.

59. Lacey DL, Boyle WJ, Simonet WS, Kostenuik PJ, Dougall WC, Sullivan JK, San Martin J, Dansey R. Bench to bedside: elucidation of the OPG-RANK-RANKL pathway and the development of denosumab. Nat Rev Drug Discov. 2012; 11(5):401-19.

60. Lacey D, Timms E, Tan H-L, Kelley M, Dunstan C, Burgess T, Elliott R, Colombero A, Elliott G, Scully S. Osteoprotegerin ligand is a cytokine that regulates osteoclast differentiation and activation. Cell. 1998;93(2):165-76.

61. Mizuno A, Kanno T, Hoshi M, Shibata O, Yano K, Fujise N, Kinosaki M, Yamaguchi K, Tsuda E, Murakami A. Transgenic mice overexpressing soluble osteoclast differentiation factor (sODF) exhibit severe osteoporosis. J Bone Miner Metab. 2002;20(6):337-44.

62. Ominsky MS, Li X, Asuncion FJ, Barrero M, Warmington KS, Dwyer D, Stolina M, Geng Z, Grisanti M, Tan HL. RANKL inhibition with osteoprotegerin increases bone strength by improving cortical and trabecular bone architecture in ovariectomized rats. J Bone Miner Res. 2008;23(5):672-82

63. Khosla S. Minireview: the opg/rankl/rank system. Endocrinology. 2001; 142(12):5050-5.

64. Nishizawa Y, Nakamura T, Ohta H, Kushida K, Gorai I, Shiraki M, Fukunaga M, Hosoi T, Miki T, Chaki O. Guidelines for the use of biochemical markers of bone turnover in osteoporosis (2004). J Bone Miner Metab. 2005;23(2):97-104.

65. Lomaga MA, Yeh W-C, Sarosi I, Duncan GS, Furlonger C, Ho A, Morony S, Capparelli C, Van G, Kaufman S. TRAF6 deficiency results in osteopetrosis and defective interleukin-1, CD40, and LPS signaling. Genes Dev. 1999:13(8): 1015-24. 
66. Zhao Q, Shao J, Chen W, Li Y-P. Osteoclast differentiation and gene regulation. Front Biosci. 2007;12(1):2519-29.

67. Zhao Q, Wang X, Liu Y, He A, Jia R. NFATc1: functions in osteoclasts. Int J Biochem Cell Biol. 2010;42(5):576-9.

68. Cagnetta V, Patella V. The role of the immune system in the physiopathology of osteoporosis. Clinical cases in mineral and bone Metabolism. 2012;9(2):85-8.

69. Roato I, Brunetti G, Gorassini E, Grano M, Colucci S, Bonello L, Buffoni L, Manfredi R, Ruffini E, Ottaviani D. IL-7 up-regulates TNF-a-dependent osteoclastogenesis in patients affected by solid tumor. PLoS One. 2006; 1(1):e124.

70. Eghbali-Fatourechi G, Khosla S, Sanyal A, Boyle WJ, Lacey DL, Riggs BL. Role of RANK ligand in mediating increased bone resorption in early postmenopausal women. J Clin Invest. 2003;111(8):1221-30.

71. Basu S, Michaëlsson K, Olofsson H, Johansson S, Melhus H. Association between oxidative stress and bone mineral density. Biochem Biophys Res Commun. 2001;288(1):275-9.

Submit your next manuscript to BioMed Central and we will help you at every step:

- We accept pre-submission inquiries

- Our selector tool helps you to find the most relevant journal

- We provide round the clock customer support

- Convenient online submission

- Thorough peer review

- Inclusion in PubMed and all major indexing services

- Maximum visibility for your research

Submit your manuscript at www.biomedcentral.com/submit 